
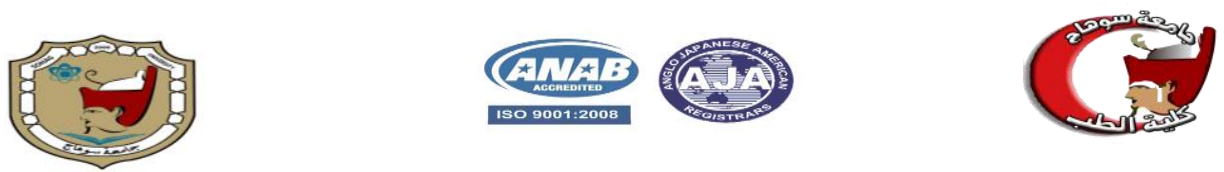

Sohag University

\title{
Levamisole in steroid dependent and frequently relapsing nephrotic syndrome
}

\author{
Ghada Ashry B. Abd-Elrehim ${ }^{1}$, Magda Mohamed Ali ${ }^{2}$
}

\author{
1-Pediatric Department, Faculty of Medicine, Sohag University \\ 2-Public Health and Community Medicine, Faculty of Medicine, Sohag University
}

\begin{abstract}
Background and aim of work: Levamisole is an antihelminthic agent with immunomodulatory properties. It resulted in a significant reduction in relapse rate and prednisone dosage in frequently relapsing and/or steroid-dependent nephrotic children with few side effects. This work aimed to study the effectiveness and side effects of levamisole as second-line therapy in patients with steroid-dependent and/or frequently relapsing nephrotic syndrome in our locality in Sohag, Egypt.

Patients and Methods: A retrospective study included records of patients with idiopathic steroid dependent and frequently relapsing nephrotic syndrome who followed in our Sohag pediatric nephrology clinic in the period from 2010 to 2020 and used levamisole. Relapse frequency/yr and steroid dependent dose before, during, and after levamisole use were calculated. Levamisole complications were recorded.

Results: It included 38 children ( 26 boys and 12 girls). Mean age at disease onset (3.9 $\pm 1.8 \mathrm{yr}$ ). Levamisole course was 3-12 months according to the response. During levamisole course; relapses stopped in $12(32 \%)$ patients, reduced in $5(13 \%)$, and were the same in $21(55 \%)$. After levamisole stoppage; no relapses were in $3(8 \%)$ patients, infrequent relapses in 11 (29\%), and frequent relapses in 24 (63\%). Frequency of relapses/yr and mean steroid-dependent dose before levamisole use were significantly higher in the failed group than in the successful group ( $P$-value 0.001 for both). No levamisole complications were recorded.
\end{abstract}

Conclusion: Levamisole is a cheap, safe, and effective drug in steroid-dependent and frequently relapsing nephrotic syndrome.

Keywords: levamisole, nephrotic syndrome, steroid dependent.

\section{Introduction}

Nephrotic syndrome (NS) is the clinical manifestation of glomerular diseases associated with heavy (nephrotic-range) proteinuria. Nephrotic syndrome affects $1-3$ per 100,000 children $<16$ yr of age. Untreated NS is associated with a high risk of death, most commonly from infections. About $80 \%$ of nephrotic children respond to corticosteroid therapy (1). Up to $80 \%$ of steroid sensitive (SS) nephrotic children have relapses. Half of these children relapse frequently and are at risk of corticosteroid adverse effects. Inspite of prolongation of the remission periods by the non-corticosteroid immunosuppressive medications, they have significant potential adverse effects. Till now, there is no assent about the most appropriate second-line agent in frequently-relapsing nephrotic children (2). Levamisole is an antihelminthic drug, with immunomodulatory characteristics (3). Tanphaichitr and coworkers described levamisole use in childhood nephrotic syndrome, for the first time in 1980 (4) and since then many studies have described its benefits (3). Levamisole is usually administered 
in a dose of $2.5 \mathrm{mg} / \mathrm{kg}$ on alternate days. Six studies revealed reduction of relapse risk by $50 \%$ with levamisole given for 4 months to 1 year $(\mathbf{5 , 6}$, and 7). The efficacy of levamisole in frequently relapsing (FR) and steroid dependent (SD) SSNS appears similar to cyclophosphamide given intravenously or orally in some studies $\mathbf{( 8 , 5 )}$. Adverse effects of levamisole are uncommon but include leucopenia, gastrointestinal effects, and occasionally vasculitis $(\mathbf{9 , 1 0})$. These data suggest that levamisole is a useful additional corticosteroid-sparing agent. However, levamisole is currently unavailable in many countries (11).

\section{Patients and Methods}

This retrospective study included patients with idiopathic SD and FR NS who used levamisole as second-line therapy. Those patients were treated and followed in our Sohag pediatric nephrology clinic, Sohag University Hospital, in the period from 2010 to 2020 . Patients' information was collected from their medical records. Inclusion criteria were (age at disease onset from 1 to12 years, idiopathic SDNS and FRNS, levamisole use for at least 3 months, and follow-up duration for at least 3 years). Exclusion criteria were (secondary NS, initial and late steroid-resistant NS, and follow-up duration for less than 3 years). Patients' demographic, clinical, and disease course data were studied. Patients' dependent steroid dose and relapses rate per year before, during, and after levamisole use were defined. Levamisole dose, duration of use, and complications were recorded. Response to other immunosuppressive drugs in those who received levamisole was also recorded if was present.

The following definitions were used $(\mathbf{1 2 , 1 3 ) : ~ N e p h r o t i c ~ s y n d r o m e ~ ( p r o t e i n - ~}$ ria $>40 \mathrm{mg} / \mathrm{h} / \mathrm{m}^{2}$ or $>50 \mathrm{mg} / \mathrm{kg} /$ day or urine protein/creatinine ratio $>0.2 \mathrm{~g} / \mathrm{m}$ mol ( $>2 \mathrm{~g} / \mathrm{g})$ and hypoalbuminemia $<25$ $\mathrm{g} / \mathrm{l}$ with or without edema), Remission (proteinuria $<4 \mathrm{mg} / \mathrm{h} / \mathrm{m}^{2}$ or 0 -trace on Albustix for 3 consecutive days or urine protein/creatinine ratio $<0.2 \mathrm{~g} / \mathrm{g}$ ), Steroid responsive (complete remission achieved with steroid therapy), Steroid resistant or initial non-responder (failure to achieve remission following 8 weeks of steroid therapy (prednisone $2 \mathrm{mg} / \mathrm{kg} / \mathrm{d}$ or $60 \mathrm{mg} / \mathrm{m}^{2} / \mathrm{d}$ for 4 weeks followed by $1.5 \mathrm{mg} / \mathrm{kg}$ or $40 \mathrm{mg} / \mathrm{m}^{2}$ per dose alternate-day for 4 weeks (14), Relapse (proteinuria $>40 \mathrm{mg} / \mathrm{h} / \mathrm{m}^{2},>50 \mathrm{mg} / \mathrm{k}$ $\mathrm{g} /$ day, urine protein creatinine ratio $\geq 2$ or Albustix +++ for 3 consecutive days after having been in remission), Infrequent relapses (one relapse within 6 months of initial response or one to three relapses in any 12-month period), Frequent relapses ( 2 or more relapses within 6 months of initial response or 4 or more relapses within a period of 1 year), Steroid dependence ( 2 consecutive relapses during corticosteroid therapy or $\mathrm{w}$ ithin 14 days after cessation of therapy), Late non responder (steroid resistance in a patient who had previously responded to corticosteroid therapy).

\section{Statistical analysis}

Statistical package for the social sciences (SPSS) version 16 was used for data analysis. Quantitative variables were presented as mean \pm standard deviation. Frequency and percentage were used for qualitative variables. For estimation of differences between qualitative variables, Chi-square and Fisher Exact Test were used.

$\boldsymbol{P}$ values less than 0.05 were considered significant.

\section{Ethical consideration}

This work was approved by the Medical Research Ethics Committee of Sohag University. All patients' data were treated according to the ethical guidelines with complete respect to patient's privacy and anonymity. 


\section{Results}

This study included 38 SD and FR nephrotic children who were followed in our Sohag pediatric nephrology clinic in the period from 2010 to 2020 and rec-

\begin{tabular}{|l|l|}
\hline Feature & Value \\
\hline Total number (patients) & 38 \\
\hline $\begin{array}{l}\text { Mean age at disease onset in } \\
\text { years }\end{array}$ & $3.9 \pm 1.8$ \\
\hline Male: female ratio & $2.16: 1$ \\
\hline Mean follow up duration & $\begin{array}{l}4.7 \pm 2 \\
\text { years }\end{array}$ \\
\hline $\begin{array}{l}\text { Mean age on levamisole } \\
\text { introduction in years }\end{array}$ & $4.7 \pm 2$ \\
\hline
\end{tabular}

Table (1): Demographic features of the included patients

On relapse, prednisone/prednisolone was given in a dose of $2 \mathrm{mg} / \mathrm{kg} /$ day till remission then on change of steroid dose to $1.5 \mathrm{mg} / \mathrm{kg} / \mathrm{eod}$; levamisole was introduced in a dose of $2.5 \mathrm{mg} / \mathrm{kg} / \mathrm{eod}$, with gradual steroid withdrawal. The duration of levamisole course in those without a change in steroid response ranged from 3 to 6 months, while those with a successful course continued to use levamisole for 12 months then stopped.

During levamisole use; no relapses were recorded in $12(32 \%)$ patients with steroid stoppage. The mean relapse rate per year decreased from 3 relapses/ year before levamisole use to $1.8 \pm 0.83$ relapses/year in $5(13 \%)$ patients with reduction in mean steroid-dependent dose from $0.6 \pm 0.1 \mathrm{mg} / \mathrm{kg} / \mathrm{eod}$ to $0.2 \pm 0.1 \mathrm{~m}$ $\mathrm{g} / \mathrm{kg} / \mathrm{eod}$. The previous patients were considered as the successful levamisole group and all together represented 45\% of patients who had received levamisole. Twenty-one $(55 \%)$ patients showed no change in relapse frequency an- eived levamisole. Mean Patients' age at disease onset was $3.9 \pm 1.8$ years. There were $26(68 \%)$ boys and $12(32 \%)$ girls. The mean follow-up duration was $4.7 \pm 2$ years. The mean age of levamisole introduction was $6.8 \pm 2.4$ years. Table (1) $\mathrm{d} /$ or steroid dependent dose, and those were considered as the failed levamisole group.

After levamisole stoppage, 3 (8\%) patients showed no additional relapses without need for steroid, 11 (29\%) patients changed to infrequent relapsers, and 24 $(63 \%)$ patients continued to have steroid dependent and/or frequently relapsing nephrotic syndrome. The mean relapse frequency per year before levamisole use was significantly higher in failed levamisole group of patients than in the successful levamisole group (3.8\pm 0.65 and $2.9 \pm 0.55$ respectively) with $(P$-value 0.001). Also higher mean dependent steroid dose was recorded in patients with levamisole failure than in those with the successful course $(0.93 \pm 0.25$ and $0.5 \pm 0.1$ respectively) with $(P$-value 0.001$)$. No levamisole complications were recorded in our patients in this study. Table (2)

Fifteen patients with failed levamisole course had used cyclophosphamide, among them 10 (67\%) patients showed good response with reduction in relapse frequency per year and/or steroid-dependent dose, and 5 (33\%) patients got no benefit from cyclophosphamide use. Twelve patients with failed levamisole course used cyclosporine; 9 (75\%) patients achieved good response with reduction of relapse frequency/year and/or steroid dependent dose and $3(25 \%)$ failed to get any benefit from cyclosporine use. 


\begin{tabular}{|l|l|}
\hline Variable & Value \\
\hline Levamisole response during its course & $15(45 \%)$ \\
Success & $21(55 \%)$ \\
Failure & \\
Mean relapse rate/year before levamisole use & $2.9 \pm 0.55$ \\
Successful group & $3.8 \pm 0.65$ \\
Failed group & 0.001 \\
$P$-value & \\
Successful group & $0.5 \pm 0.1$ \\
Failed group & $0.93 \pm 0.25$ \\
$P$-value & 0.001 \\
\hline Mean dependent steroid dose before levamisole use in $\mathrm{mg} / \mathrm{kg} /$ eod & \\
$12(32 \%)$ patients & Zero \\
$5(13 \%)$ patients & $1.8 \pm 0.83$ \\
$21(55 \%)$ patients & $3.8 \pm 0.65$ \\
\hline Mean relapse rate/year during levamisole use & \\
$5(13 \%)$ patients & Zero \\
$21(55 \%)$ patients & $0.2 \pm 0.1$ \\
\hline Mean dependent steroid dose during levamisole in $\mathrm{mg} / \mathrm{kg} / \mathrm{eod}$ & $0.93 \pm 0.25$ \\
\hline (8\%) patients & \\
\hline Levamisole complications & Zero \\
\hline Mean relapses/year after levamisole stoppage & $1.6 \pm 0.6$ \\
\hline (29) patients & $3.9 \pm 0.75$ \\
\hline (2) patients & Zero \\
\hline
\end{tabular}

Table (2): Steroid response before, during, and after levamisole use

\section{Discussion}

Patients with SDNS and FRNS are candidates for complications of prolonged steroid therapy. In 1980, levamisole was first described in childhood NS. It was found to be an effective second-line therapy in steroid sensitive nephrotic children to decrease steroid needs and relapse frequency. The British Association of Pediatric Nephrology study published in 1991 the first controlled study about the significant reduction of the disease relapse frequency in childrenn used levamisole (15). Variable results then were obtained in various studies.

In our study levamisole was used in 38 patients at a dose of $2.5 \mathrm{mg} / \mathrm{kg} / \mathrm{eod}$. During the levamisole course; $17(45 \%)$ patients achieved success, and $21(55 \%)$ patients failed to achieve any benefit from its use. Relapses were stopped in $12(32 \%)$ patients with steroid stop-age, while $5(13 \%)$ patients showed a reduction in mean relapse frequency/year from 3 to $1.8 \pm 0.83$ relapses/year and reduction in the mean steroid-depen- dent dose from $0.6 \pm 0.1 \mathrm{mg} / \mathrm{kg} / \mathrm{eod}$ to $0.2 \pm 0.1 \mathrm{mg} / \mathrm{kg} / \mathrm{eod}$. After levamisole stoppage; 3 (8\%) patients showed no additional relapses without need for steroids, $11(29 \%)$ patients continued as infrequent relapsers with mean relapse frequency/year 1.6 \pm 0.6 , while $24(63 \%)$ patients continued as SD and/or FR with mean relapse frequency/year $3.9 \pm 0.75$.

A higher success rate was achieved in other studies as in a Pakistanian study where levamisole was effective in $90 \%$ of patients during levamisole use, while $76.5 \%$ maintained remission, and $23.5 \%$ behaved as FR/SD after levamisole stoppage. (16).

In Madani et al study, there was a significant reduction of steroid dose with levamisole use. The mean steroid cumulative dose was reduced to $46 \%$ of the pre-levamisole dose, after levamisole use. Mean relapse frequency significantly decreased from $1.99 \pm 2.18$ to $1.07 \pm 1.20$ episodes per year. A significant correlation was detected bet- 
ween levamisole treatment duration with both steroid dose reduction and relapse frequency reduction (17).

In an Indian study; both alternate day and daily levamisole therapy were used. Alternate day levamisole therapy was effective in $73.7 \%$. Daily levamisole therapy was useful in $56 \%$ of children with failed alternate day levamisole therapy and could be a useful therapeutic option in FRNS and SDNS, with an overall efficacy of levamisole therapy $88.4 \%$. In this study, $48.8 \%$ of patients with successful levamisole courses resumed FR or SD course after levamisole stoppage necessitating oral cyclophosphamide or mycophenolate mofetil (18).

Ekambaram $\mathrm{S}$ et al demonstrated that levamisole was effective in $77.3 \%$ of SD or FR nephrotic children, with better efficacy in FR as compared to SD nephrotic syndrome. There was a reduction of the mean cumulative steroid dose to $16 \%$ of pre-levamisole use, after its use. Relapse frequency was less after levamisole use compared to before its use. No levamisole side effects were observed even when used daily for 2 years (19).

In our study, 15 patients with failed levamisole course had used cyclophosphamide, among them 10 (67\%) patients showed good response with reduction in relapse frequency per year and/or steroid-dependent dose, and 5 (33\%) patients got no benefit from cyclophosphamide use. So cyclophosphamide achieved success in about $2 / 3$ of patients with failed levamisole course, but cyclophosphamide side effects should be put in mind compared with little or no levamisole complications. Twelve $\mathrm{p}$ atients with failed levamisole course used cyclosporine; 9 (75\%) patients achieved good response with reduction of relapse frequency/year and/or steroiddependent dose and 3 (25\%) failed to get any benefit from cyclosporine use. So better results were achieved with cyclosporine, but cyclosporine nephrotoxicity, dependence, and high price should be considered.

An Egyptian study in 2002 concluded that; use of levamisole for 6 months was effective and safe therapy in a group of patients with SD minimal change disease allowing withdrawal of steroid. The authors suggested the trial of levamisole in SD nephrotic syndrome before other more hazardous second line medications (20).

Other studies showed variable levamisole effectiveness in comparison with other non-steroidal immunosuppressive drugs. In Alsatian K et al study of 60 children, there were significant reductions in both the mean relapse rate and the cumulative dose of steroids with all 4 (levamisole, cyclophosphamide, cyclopssorine, and mycophenolate mofetil) second-line drugs $(\mathrm{P}<$.0001) (21).

No levamisole complications were recorded in our patients during its course. This is the same as in Ekambaram $\mathrm{S}$ et al study (19) and Samuel E et al study (18). In Alsatian $K$ et al study; 4 cases developed transient neutropenia during levamisole use, resolved with its discontinuation (21). One case developed pancytopenia and another developed allergic rashes, in the Moorani KN et al study (16).

The major limitation of this study is the small number of patients and the absence of comparison with other secondline mediations as regard to efficacy and side effects. Additional studies are needed to compare various second-line medications, in order to determine the best first choice in patients with SD and FR nephrotic syndrome. There was the absence of a control group, but this study depended on the comparison between the disease course before and after levamisole use in the same patients to show its effectiveness.

In conclusion, levamisole is a cheap and relatively drug for the management of SD and FR nephrotic syndrome. Leva- 
misole succeeded to decrease steroiddependent dose and/or relapse frequency in about half of our patients during its use and about one-third after its stoppage. The mean steroid-dependent dose and relapse frequency per year before levamisole use were significantly higher in those with failed levamisole courses than in those with the successful course. About two-thirds of patients with failed levamisole course who used cyclophosphamide have got benefit with its use. While a higher percentage got benefit from cyclosporine use.

Financial support: None.

Conflict of interest statement: None declared

\section{References}

1. Erkan E. Nephrotic syndrome. In: Kliegman RM, Stanton BF, Geme JW, Schor NF, Behrman RE editors: Nelson Textbook of pediatrics, 21st ed, Philadelphia, Elsevier Inc, 2020; 545(1):10806-10835.

2. Larkins, N. G., Liu, I. D., Willis, N. S., Craig, J. C., \& Hodson, E. M. Noncorticosteroid immunosuppressive medications for steroid-sensitive nephrotic syndrome in children. Cochrane Database of Systematic Reviews. 2020; 4. https://doi.org/10.1002/14651858.CD0 02290.pub5

3. Davin JC, Merkus MP. Levamisole in steroid-sensitive nephrotic syndrome of childhood: the lost paradise? Pediatr Nephrol. 2005; 20 (1):10-4.

4. Tanphaichitr P, Tanphaichitr D, Sureeratanan J, Chatasingh S. Treatment of nephrotic syndrome with levamisole. J Pediatr. 1980; 96 (3 Pt 1):490-3.

5. Sural S, Pahari DK, Mitra K, Bhattacharya S, Mondal S, Taraphder A. Efficacy of levamisole compared to cyclophosphamide and steroid in frequently relapsing (FR) minimal change nephrotic syndrome (MCNS) [abstract]. J Am Soc Nephrol. 2001; 12:126A.
6. Dayal U, Dayal AK, Shastry JC, Raghupathy P. Use of levamisole in maintaining remission in steroidsensitive nephrotic syndrome in children. Nephron. 1994; 66 (4):40812. Erratum appears in Nephron 67(4):507.

7. Al-Saran K, Mirza K, Al-Ghanam G, Abdelkarim $M$ Experience with levamisole in frequently relapsing, steroid-dependent nephrotic syndrome. Pediatr Nephrol. 2006; 21(2):201-5.

8. Donia AF, Ammar HM, El-Agroudy AE-B, Moustafa FE-H, Sobh MA-K. Long-term results of two unconventional agents in steroiddependent nephrotic children. Pediatr Nephrol. 2005; 20(10):1420-5.

9. Palcoux JB, Niaudet P, Gaumy P. Side effects of levamisole in children with nephrosis. Pediatr Nephrol. 1994; 8(2):263-4.

10.Barbano G, Ginevra F, Ghiggeri GM, Gusmano R. Disseminated autoimmune disease during levamisole treatment of the nephrotic syndrome. Pediatr Nephrol. 1999; 13(7):602-3.

11.Hodson EM, Alexander SI, Graf N. Steroid Sensitive Nephrotic Syndrome. In: Geary DF, Schaefer F Editors: Pediatric Kidney Disease, Second Edition, Springer-Verlag Berlin Heidelberg 2016; 15:419-453.

12. Niaudet P, Boyer O: Idiopathic nephrotic syndrome in childhood: clinical aspects. In: Avner ED, Harmon WE, Niaudet P, Yoshikawa N, Emma F, Goldstein SL editors: Pediatric Nephrology, 7th edition, Heidelberg, Germany, Springer-Verlag, 2016; 839882.

13.KDIGO (Kidney Disease Improving Global Outcomes) Glomerulonephritis Work Group. KDIGO clinical practice guideline for glomerulonephritis. Kidney Int Suppl 2012; (2):139-274.

14.Gipson DS, Massengill SF, Yao L, Nagaraj S, Smoyer WE, Mahan JD, et al. Management of childhood-onset nephrotic syndrome. Pediatrics. 2009; 124(2):747-757.

15.British Association for Paediatric Nephrology Levamisole for corticosteroid-dependent nephrotic 
syndrome in childhood. Lancet. 1991; 337:1555-1557.

16.Moorani KN, Zubair AM, Veerwani NR, Hotchandani HJ. Efficacy of Levamisole in children with Frequent Relapsing and Steroid Dependent Nephrotic Syndrome at Tertiary Care Center-Karachi. Pak J Med Sci. 2020; 36(6):1193-1198.

17.Madani A, Isfahani S-T, Rahimzadeh N, Fereshtehnejad S-M, Hoseini R, Moghtaderi M, et al. Effect of levamisole in steroid-dependent nephrotic syndrome. Iran J Kidney Dis. 2010; 4(4):292-6.

18.Samuel, E.M.K., Krishnamurthy, S., Bhanudeep, S. et al. Levamisole in frequently-relapsing and steroiddependent nephrotic syndrome. Indian Pediatr. 2017; 54: 831-834.
19.Ekambaram

Nageswaran

S, Mahalingam V,

Geminiganesan S, Priyadarshini S. Efficacy of levamisole in children with frequently relapsing and steroiddependent nephrotic syndrome. Indian Pediatr. 2014 May; 51(5):371-3.

20.Donia, A., Amer, G., Ahmed, H. et al. Levamisole: adjunctive therapy in steroid dependent minimal change nephrotic children. Pediatr Nephrol 2002; 17, 355-358.

21. Alsaran K, Mirza K, Al-Talhi A, AlKanani E. Experience with second-line drugs in frequently relapsing and steroid-dependent childhood nephrotic syndrome in a large Saudi center. Int $\mathbf{J}$ Pediatr Adolesc Med. 2017; 4(2):66-70. 